\title{
AN ORDINARY MICROSCOPE ADAPTED TO METALLOGRAPHY.
}

\author{
By F. IAN G. Rawlins, F.R.M.S.
}

The purpose of the following brief note is to draw attention to certain details of a more or less minor nature, which, when incorporated into an ordinary microscope stand, render it decidedly efficient for metallographical work, where an elaborate outfit is not desired. Although post-war models are now appearing by the leading makers for this brauch of microscopy, there is a decided advantage in being able to use an ordinary stand, and the expense involved in the modifications is very moderate. Lastly, the additions are such that they can be easily carried out, even in the present abnormal state of the trade; and they are no detriment to work on trans. parent objects.
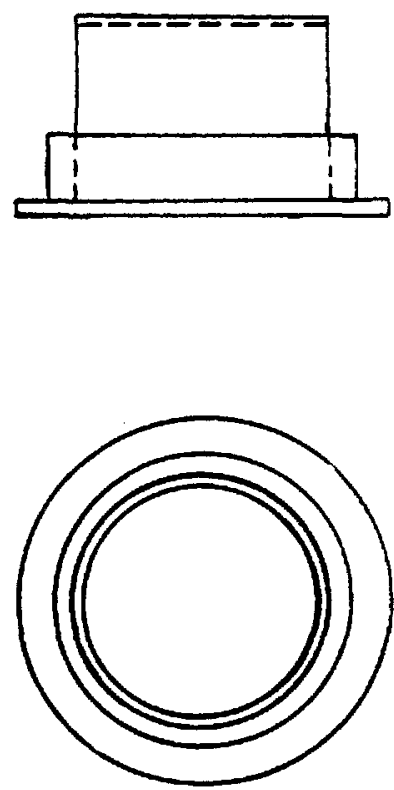

FIG. I.

Vertical and Horizontal Sections of Plug.

\section{(1) Substage Fitting.}

The point of this is to overcome the trouble inherent in the use of ordinary stands for opaque objects with the vertical illuminator, i.e., that on re-focussing, the centering of the illuminator and light. source is disturbed. Assuming that the stand possesses no substage apparatus (apart from the mirror), a focussing substage is fitted, provided with coarse adjustment, rack and pinion. Instead of the usual condenser, a solid brass plug (circular, and of the shape 
sketched in vertical section,) is inserted into the ring. The top is provided with a slightly bevelled edge, into which fits a glass slip on which the plasticine holding the specimen is placed as usual. This can then be focussed upwards and downwards, avoiding any movement of the body-tube. To substitute another specimen, all that is needed is to rack down, swing the fitting out of the optic axis, take out the plug, insert another levelled specimen as already described, re-insert the plug, and focus as before. Of course, if only objectives are being changed, the focus can be re-set at once. An adapter fitted to the body-tube may be wanted if the rackwork on the stand is limited. The central aperture in the stage is generally too small, and should be enlarged for these additions. In the event of transparent work with condenser, polariser, etc., being contemplated, the focussing substage is ready at hand, the appropriate fitting being substituted for the afore-mentioned plug.

(2) Objectives.

Mounting in short barrels is very desirable for use with the vertical illuminator. There is often considerable difficulty in obtaining objectives so arranged from the makers. The following alteration, easily carried out, may assist. The lower part of the barrel is
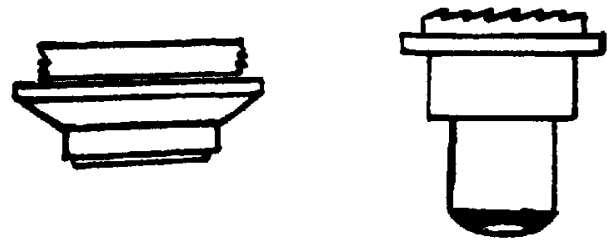

FIG. 2.

Carrier and Unscrewed Part of Objective.

unscrewed, and then inserted into a carrier bodily, which latter is provided with a standard thread, attaching to the vertical illuminator, and bringing the back lens of the objective very close to the reflector. Two lenses so treated, a $\frac{1}{3}$ inch and a $\frac{1}{6}$ inch, in the writer's possession give excellent results in practice.

\section{(3) Illumination.}

A type of "Half-Watt" lamp made in Holland has been found admirable. The 200 candle-power size is amply sufficient. By noting that the ring-filament in these lamps gives a very solid and concentrated area of light, and using a bull's-eye condenser of small aperture, it is possible to get effects closely resembling a "point-source" of light. The very moderate cost of these lamps compared with, say, a "Pointolite," is greatly in their favour, and they are quite powerful enough for magnifications up to 600 diameters in metallography.

In conclusion, apart from general ideas, the author disclaims any question of having originated the above improvements. His thanks are due to Messrs. H. F. Angus and $\mathrm{Co}$. for their skilled assistance. 